\title{
Altered Patterns of Dynorphin Immunoreactivity Suggest Mossy Fiber Reorganization in Human Hippocampal Epilepsy
}

\author{
C. R. Houser, ${ }^{1,2,4}$ J. E. Miyashiro, ${ }^{4}$ B. E. Swartz, ${ }^{1,3}$ G. O. Walsh, ${ }^{1,3}$ J. R. Rich, ${ }^{5}$ and A. V. Delgado-Escueta ${ }^{1,3,4}$ \\ ${ }^{1}$ California Comprehensive Epilepsy Program and Southwest Regional Epilepsy Center, Neurology and Research Services, \\ Veterans Administration Medical Center, West Los Angeles, Wadsworth Division, Los Angeles, California 90073, \\ Departments of ${ }^{2}$ Anatomy and ${ }^{3}$ Neurology and ${ }^{4}$ Brain Research Institute, University of California School of Medicine, Los \\ Angeles, California 90024, and ${ }^{5}$ Department of Surgery/Neurosurgery, Santa Monica Hospital, Santa Monica, California \\ 90404
}

Dynorphin $A(1-17)$, an opioid peptide that is normally present in the hippocampal mossy fiber system, was localized immunocytochemically in the hippocampal formation of control autopsy and temporal lobe epilepsy (TLE) specimens. In control tissue, dynorphin-like immunoreactive (Dyn-IR) structures were confined to the mossy fiber path and were most highly concentrated in the polymorph (hilar) region of the dentate gyrus. Very few Dyn-IR structures were present in the molecular and granule cell layers of the dentate gyrus. In contrast, in all TLE specimens, Dyn-IR elements were present in these layers. The extent of aberrant staining varied among the TLE specimens, and 2 major patterns were observed. The first was a relatively wide band of reaction product in the inner one-third to one-fourth of the molecular layer ( 8 cases), and the second was a more limited distribution of immunoreactive fibers and presumptive terminals in the granule cell and immediately adjacent supragranular regions (2 cases). The extent of aberrant Dyn-IR structures appeared to be related to the amount of cell loss in the polymorph and CA3 fields and to dispersion of the granule cell somata. Specimens processed with the Timm's sulfide silver method for heavy metals provided independent evidence for the distribution of mossy fibers. In both control and TLE specimens, the patterns of labeling were virtually identical to those of dynorphin localization. These findings suggest that sprouting of mossy fibers or their axon collaterals has occurred in hippocampal epilepsy and that the reorganized fibers contain at least one of the neuropeptides that are normally present in this system. Such fibers could form recurrent excitatory circuits and contribute to synchronous firing and epileptiform activity, as suggested in studies of experimental models of epilepsy.

\footnotetext{
Received Apr. 14, 1989; revised June 28, 1989; accepted July 10, 1989
}

We thank Dr. R. W. Rand, Dr. P. S. Dwan and members of the Surgical and Pathology Staffs of Santa Monica Hospital for their assistance during the study, Dr. L. Terenius for providing antiserum to dynorphin A, and S. Pietsch for administrative help. We gratefully acknowledge the support of the National Neurological Specimen Bank, directed by W. W. Tourtellotte, Veterans Administration Medical Center, West Los Angeles, California, in obtaining the autopsy specimens. This research was supported by VA Medical Research Funds and NIH grant NS21908.

Correspondence should be addressed to Dr. Carolyn R. Houser, BRI 73-364 CHS, UCLA-Brain Research Institute, Los Angeles, CA 90024-1761.

Copyright (C) 1990 Society for Neuroscience 0270-6474/90/010267-16\$02.00/0
One intriguing anatomical feature of the hippocampal formation in temporal lobe epilepsy (TLE) of the hippocampal type is the selectivity of cell loss. While some groups of neurons are relatively well preserved, other immediately adjacent groups may be substantially depleted. Consequently, the normal circuitry of the hippocampal formation is severely disrupted. Although much attention has been focused on cell loss (Sommer, 1880; Mouritzen Dam, 1980; Babb et al., 1984), the anatomical organization and function of the remaining neurons are equally important since they presumably play a critical role in the initiation and propagation of seizures. Such remaining neurons include the dentate granule cells and CA2 neurons that are often relatively well preserved despite the moderate to severe loss of neurons in the hilus, CAl and CA3 fields (Margerison and Corsellis, 1966; Meldrum and Corsellis, 1985; Bruton, 1988).

Numerous studies in experimental animals have shown that selective neuronal loss in the hippocampus can lead to synaptic reorganization of the remaining neurons (see Cotman and Nadler, 1978, for review), and it is possible that similar forms of neuronal reorganization could occur in humans. The potential rearrangement of granule cell axons or mossy fibers, which normally innervate neurons in the hilus and CA3 field of the hippocampus, is of particular interest since these fibers are a major excitatory link in the circuitry of the hippocampal formation (Andersen et al., 1966).

In the rodent hippocampal formation, mossy fibers have a propensity for normal variations in their distribution and for several types of morphological reorganization (Zimmer, 1973; Barber et al., 1974; Lauder and Mugnaini, 1980; Nadler et al., 1980; West, 1984; West and Dewey, 1984; Represa et al., 1987). Such reorganization includes supragranular sprouting of mossy fibers, as first demonstrated in rats following partial deafferentation of the dentate gyrus by lesions of the perforant path (Zimmer, 1973, 1974). Later studies demonstrated that more extensive supragranular sprouting occurred following deafferentation of the granule cclls by lesions of association projections from the hilus (Laurberg and Zimmer, 1981). Nadler et al. (1980) also described sprouting of the mossy fibers following kainic acid treatment, and these findings have been confirmed by other investigators (Tauck and Nadler, 1985; Cronin and Dudek, 1988). Since kainic acid injections produce relatively selective loss of neurons in the hilus, CA3 and CA4 fields, they create a pattern of cell loss that is similar in several respects to that of TLE (Nadler et al., 1983; Ben-Ari, 1985). Like direct lesions, kainic 
acid-induced cell loss presumably produces partial deafferentation of the molecular layer that could serve as a stimulus for sprouting. However, mossy fiber sprouting may also occur without cell loss. Recently, Sutula et al. (1988) and Represa et al. (1989a) observed supragranular staining of mossy fibers in the absence of overt morphological damage in kindled animals. Stanfield (1989) also found intra- and supragranular mossy fibers in the tottering mouse, which exhibits spontaneous seizures but shows no obvious signs of deafferentation. Such observations have led to the suggestion that abnormal activity alone could cause structural reorganization of neuronal pathways, which, in turn, might promote epileptogenesis (Sutula et al., 1988).

Thus, the goals of the present study were to determine if alterations of the mossy fiber path, similar to those described in animal studies, occur in humans with TLE and to relate such changes to the pattern and degree of cell loss. Two neuroanatomical methods were used to study the distribution and potential reorganization of hippocampal mossy fibers in human tissue. The first was the immunocytochemical localization of dynorphin $\mathrm{A}$, an opioid peptide that is present in the mossy fibers and terminals of many species, including mouse, rat, guinea pig, and monkcy (Khachaturian ct al., 1982; McGinty ct al., 1983; Gall, 1988; Herkenham and McLean, 1988). The second was the Timm's stain for heavy metals that depends on the normally high content of zinc in mossy fiber terminals (Haug, 1973; Frederickson et al., 1983). A preliminary report of the findings has been published (Houser and Miyashiro, 1988).

\section{Materials and Methods}

\section{Patients and control cases}

Surgical specimens were obtained from 10 patients with medically intractable TLE. Seven males and 3 females ranged in age from 19 to 39 years (mean $=29.2$ years) at the time of surgery. All had complex partial seizures, and 9 also had secondary tonic-clonic seizures at some timc in the course of the disease. The age at onset of epilepsy was 1.5-23 years $($ mean $=10.5)$, and the duration of epilepsy was 12-28 years (mean $=18.8$ ). Four of the patients had experienced seizures during the $48 \mathrm{hr}$ prior to surgery. No patients had tumors or structural lesions as evidenced by computed tomography (CT) or magnetic resonance imaging (MRI), but 8 of 10 patients showed increased T2 signal intensity on MRI in the medial temporal region, and one showed unilateral enlargement of the temporal horn of the lateral ventricle. Positron emission tomography (PET) revealed unilateral hypometabolism in the temporal lobe of 9 patients. The absence of tumors or other structural lesions was confirmed postsurgically by pathological examination of excised tissues.

Control autopsy specimens from the hippocampus of 10 unfixed brains were obtained from the Human Neurological Specimen Bank, VA Wadsworth Medical Center, Los Angeles, CA. The cases, 9 males and 1 female, had no known history of neurological disease. Tissue from 6 cases was used for immunocytochemistry and cresyl violet-stained preparations from which neuronal cell counts were made. These cases were 44-77 years of age (mean $=60.0$ ), and the autolysis times ranged from 8 to $28 \mathrm{hr}$ (mean $=16.7$ ). Specimens from 4 additional cases were used for Timm's staining. These cases were $15-71$ years of age $($ mean $=47.5)$, and autolysis times were $11-28 \mathrm{hr}($ mean $=20.0)$.

\section{Immunocytochemistry}

Specimens from the hippocampal formation of surgical TLE and autopsy specimens were sectioned coronally into 3- to 5-mm-thick blocks. Specimens to be used for immunocytochemistry were immersed in 4\% paraformaldehyde in $0.12 \mathrm{M}$ phosphate buffer $(\mathrm{pH} \mathrm{7.3)}$ for $2-3 \mathrm{hr}$. After thorough rinsing in phosphate buffer and infiltration with a $20 \%$ sucrose solution, the specimens were frozen with dry ice, and 30- $\mu \mathrm{m}$-thick coronal sections were cut on a cryostat. Sections were rinsed in $0.1 \mathrm{M}$ Tris buffer ( $\mathrm{pH} \mathrm{7.4)}$ and stored in serial order in the same buffer until im- munocytochemical processing. Every 10 th section was stained with $0.5 \%$ cresyl violet for general analysis of the tissue and cell counting.

Two rabbit antisera to dynorphin A were used in this study (L. Terenius, Uppsala, Sweden; Peninsula Laboratories). Cross-reactivity of the first dynorphin A antiserum (84+, L. Terenius) with dynorphin A(18), dynorphin A(1-13), dynorphin B, [Leu]enkephalin, [Leu]enkephalin$\mathrm{Arg}^{6}$, [Met]enkephalin, and $\alpha$-neoendorphin was $<0.1 \%$. Cross-reactivity with dynorphin $\mathrm{A}(9-17)$ was $100 \%$ (Christensson-Nylander and Terenius, 1985). The second dynorphin A antiserum (Peninsula Laboratories) showed no detectable cross-reactivity with dynorphin $A(1-8)$, [Leu]enkephalin, or [Met]enkephalin. Cross-reactivity with dynorphin $A(1-13)$ and dynorphin $A(1-17)$ was 42 and $100 \%$, respectively (technical information from Peninsula Laboratories). Both antisera showed similar patterns of hippocampal mossy fiber labeling in immunocytochemical specificity tests in rats, and the patterns were comparable to those described in previous studies of dynorphin A localization (McGinty et al., 1983; Gall, 1988).

Tissue from the hippocampal formation was processed for immunocytochemistry by an unlabeled antibody peroxidase-antiperoxidase (PAP) method (Sternberger, 1979; Houser et al., 1988). Prior to this processing, the tissue was incubated in a $0.5-1.0 \%$ solution of hydrogen peroxide in Tris buffer for $30 \mathrm{~min}$ to reduce endogenous peroxidase activity and then rinsed in Tris-buffered saline solution (TBS; $0.1 \mathrm{M}$ Tris buffer, $\mathrm{pH} 7.4$, containing an additional $1.0 \% \mathrm{NaCl}$ ). The immunocytochemical procedures consisted of the following steps:

1. Incubation in normal goat serum (diluted 1:30 in TBS containing $0.5 \%$ Triton X-100) for $1 \mathrm{hr}$. TBS containing $1.0 \%$ normal goat serum was used for diluting the remaining reagents.

2. Incubation in dynorphin A antiserum (Peninsula Laboratories or L. Terenius, diluted 1:2000-1:4000) for $6 \mathrm{hr}$ at room temperature and an additional $18 \mathrm{hr}$ at $4^{\circ} \mathrm{C}$. Control incubations consisted of similar incubations in antisera that had been preabsorbed with $50 \mu \mathrm{M}$ dynorphin A(1-17) (Bachem).

3. Incubation in species-specific goat anti-rabbit IgG serum that had been adsorbed to human IgG (American Qualex; diluted 1:75) for $1 \mathrm{hr}$

4. Incubation in rabbit PAP complex (Sternberger Meyer; diluted $1: 100$ ) for $1 \mathrm{hr}$.

Following each of the last 3 steps, the tissue was rinsed thoroughly in TBS. The sections were then reacted for $15 \mathrm{~min}$ with $0.006 \% 3,3^{\prime}$ diaminobenzidine $\cdot \mathrm{HCl}$ and $0.006 \% \mathrm{H}_{2} \mathrm{O}_{2}$, diluted in $\mathrm{PBS}$, pH 7.3. Sections were rinsed, treated for $30 \mathrm{sec}$ in $0.05 \%$ osmium tetroxide, rinsed again, and then mounted on slides. Sections were air-dried, dehydrated, and coverslipped.

\section{Timm's staining}

Specimens to be processed for Timm's staining were frozen following an 11-28 hr autolysis time. Since such time had elapsed for the autopsy specimens, the tissue was immediately frozen. However, additional time was needed to obtain comparable surgical specimens. Thus, these specimens were moistened with artificial cerebrospinal fluid, Elliott's Solution B (Elliott, 1984), and incubated in a tightly closed container at $35^{\circ} \mathrm{C}$ for $22-24 \mathrm{hr}$ prior to freezing on dry ice. Tissue sections $(20 \mu \mathrm{m})$ were then cut on a cryostat and thaw-mounted onto acid-cleaned microscope slides in preparation for Timm's staining.

The Timm's staining method for nonsulfide-perfused human tissue (Cassell and Brown, 1984) was used in the present study because it could be applied to both surgical and autopsy tissue. After the unfixed hippocampal sections were thaw-mounted onto slides, they were dried for $3 \mathrm{hr}$ and then fixed in $95 \%$ ethanol for $15 \mathrm{~min}$ and rehydrated through $70 \%$ ethanol to $\mathrm{H}_{2} \mathrm{O}$. The sections were incubated in modified Timm's developer (Danscher and Zimmer, 1978) in the dark at $26^{\circ} \mathrm{C}$ for a series of times ranging from $60-90 \mathrm{~min}$. The slides were then rinsed thoroughly with water while in the dark and transferred to $95 \%$ ethanol overnight to prevent fading of the reaction product. The following day, the sections were counterstained with $0.5 \%$ cresyl violet, dehydrated, and coverslipped.

\section{Data analysis}

Scoring system for dynorphin localization. Sections from each patient were given a score of $0-3$ to describe the relative amounts of supragranular staining. A score of 0 was assigned if there were virtually no stained processes in the granule cell and supragranular layers. A score of 1 was given if dynorphin-like immunoreactive (Dyn-IR) structures were present predominantly in the granule cell layer or immediately 


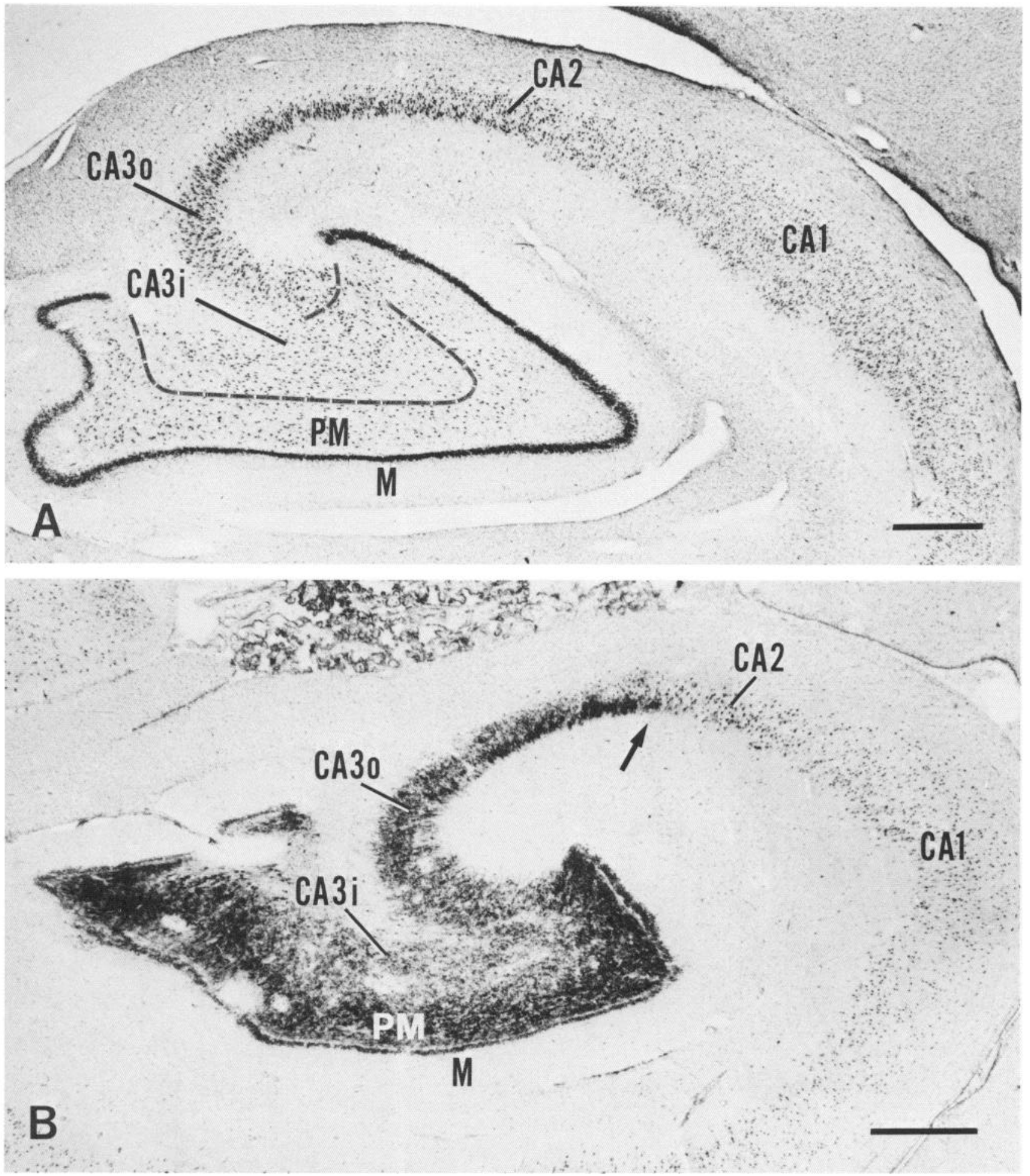

Figure 1. Control autopsy specimens of the hippocampal formation. $A$, In a coronal section stained with cresyl violet for the demonstration of neuronal cell bodies, the approximate borders between the polymorph $(P M)$, inner CA3 $(C A 3 i)$, and outer CA3 $(C A 3 o)$ zones are indicated by dashed lines. $B$, In a coronal section stained by the Timm's sulfide silver method for heavy metals, dark precipitate is present in regions that correspond to the mossy fiber path. Staining is heaviest in the polymorph $(P M)$ layer and becomes slightly lighter in the adjacent CA3i field. Staining is present throughout the pyramidal cell layer of CA3o and ends in an angle at the border between CA3 and CA2 (arrow). No staining is present in the molecular $(M)$ layer of the dentate gyrus. The section has been counterstained with cresyl violet for visualization of neuronal cell bodies. Scale bars, $1 \mathrm{~mm}$. 


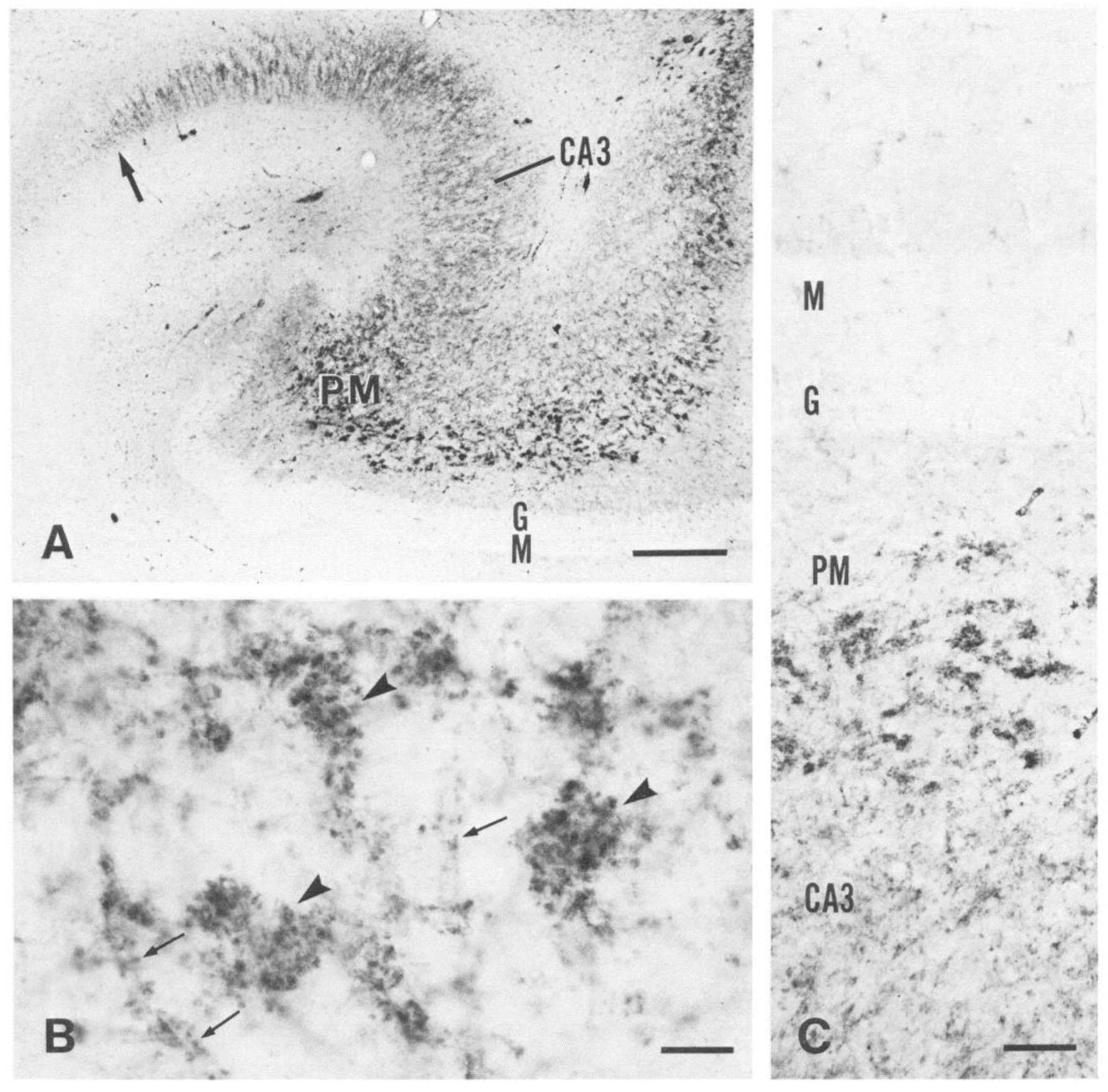

Figure 2. Dynorphin-like immunoreactivity in coronal sections of the hippocampal formation of a control, autopsy specimen. $A$, Dyn-IR structures are most highly concentrated in the polymorph $(P M)$ region and are also present throughout the CA 3 field. The staining ends in an angle at the junction of CA3 and CA2 (arrow). No specific staining is evident in the granule cell $(G)$ layer or supragranular region of the molecular $(M)$ layer. Scale bar, $500 \mu \mathrm{m}$. B. Within the polymorph layer, reaction product is concentrated in clumps (arrowheads) of punctate structures near the proximal portions of neurons. In addition, labeled punctate structures appear to outline dendrites (arrows) in this region. Scale bar, $25 \mu \mathrm{m}$. $C$, In a panel through the dentate gyrus and inner CA3 field, virtually no reaction product is evident in the inner molecular $(M)$ and granule cell $(G)$ layers. In contrast, labeled structures are highly concentrated around neuronal elements in the polymorph $(P M)$ region and become more evenly distributed throughout the CA3 field. Scale bar, $100 \mu \mathrm{m}$.

adjacent supragranular region or if only a few labeled fibers were observed in the inner molecular layer. A score of 2 was assigned if a light but wider band of immunoreactive elements was present in the inner molecular layer and extended throughout most of the medial-lateral extent of the layer. A score of 3 was given if a dark band of staining, consisting of a high concentration of Dyn-IR structures, was present in the inner one-fourth to one-third of the molecular layer and extended throughout the medial-lateral extent of the dentate gyrus.

Neuron counts. The cresyl violet-stained sections from control and
TLE cases were examined to determine the general morphological characteristics of the tissue, and neurons were counted in 3 regions that normally receive innervation from mossy fiber terminals of the granule cells (Fig. 1, $A, B$ ). The first was the polymorph or hilar region that extends approximately $600 \mu \mathrm{m}$ deep to the granule cell layer and consists of several morphologically and chemically distinct classes of neurons (Ramón y Cajal, 1893; Amaral, 1978; Amaral et al., 1988; Amaral and Insausti, 1989). It is likely that this region contains neurons that other investigators have included in CA4. However, due to contradictory 


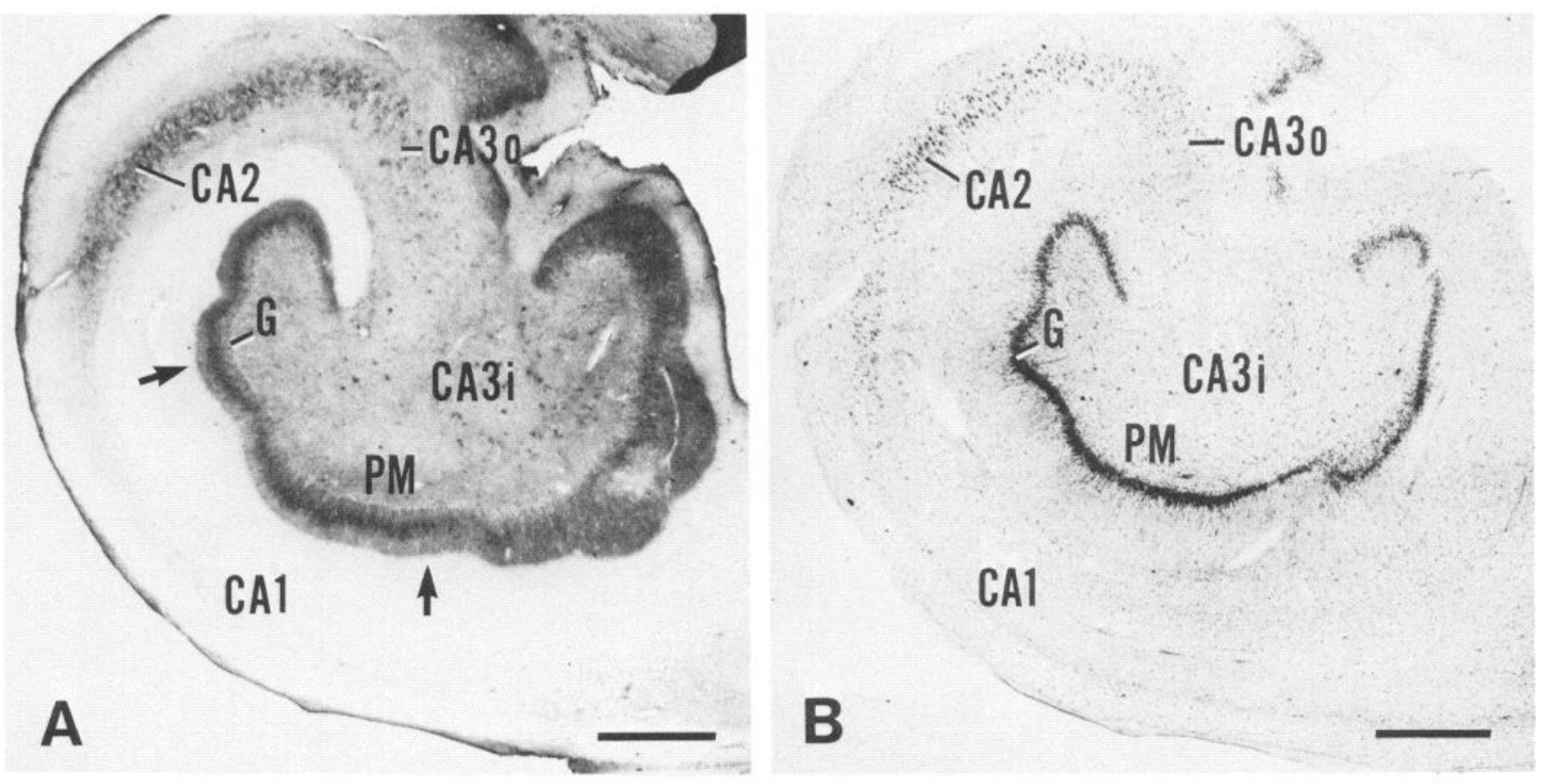

Figure 3. Patterns of dynorphin-like immunoreactivity and cresyl violet staining of neuronal cell bodies in adjacent coronal sections from the hippocampal formation of a patient with hippocampal epilepsy. $A$, A densely stained band of Dyn-IR structures (arrows) is evident in the inner molecular layer and extends throughout the medial-lateral extent of the dentate gyrus. The narrow, lightly stained region immediately deep to the band is the granule cell $(G)$ layer. Relatively low concentrations of reaction product are present in the polymorph $(P M)$ and CA3i field, where there is severe neuronal loss (see $B$ ). Higher concentrations of reaction product are evident in the distal part of CA3o and extend into the presumptive CA2 field. $B$, Neurons in the dentate granule cell $(G)$ layer and CA2 field appear relatively well preserved. However, severe neuronal loss is evident in the polymorph $(P M), C A 3 i$ and CAl regions. Varying degrees of cell loss are found in CA3o. Scale bars, $1 \mathrm{~mm}$.

descriptions of the CA4 field (see Amaral, 1978; Amaral and Insausti, 1989 , for discussion), the term has not been used in the present study. The group of neurons adjacent to the polymorph layer was considered part of $\mathrm{CA} 3$, and the neurons of this field that remained within the boundaries of the dentate gyrus were designated the inner CA3 field (CA3i), the second region in which cells were counted. The final region for cell counting was the continuation of the CA3 field beyond the dentate gyrus, where the pyramidal neurons are more densely organized and assume a similar, parallel, orientation, and this was designated the outer CA3 field (CA3o).

While it was relatively easy to distinguish these regions in control specimens, it was more difficult to determine the boundaries of the regions in TLE specimens. Thus, for consistency, cell counts in the polymorph region were made in an area near the relatively straight inferior limb of the dentate gyrus. The area was $1000 \mu \mathrm{m}$ in length and extended from $100 \mu \mathrm{m}$ above the inner border of the granule cell layer to $600 \mu \mathrm{m}$ into the hilus, and, thus, included the polymorph region with moderate cell densities but excluded the cell-sparse zone that lies immediately adjacent to the granule cell layer. Cell counts in the CA3i and $\mathrm{CA} 3 \mathrm{o}$ fields were made within regions of the same size that were located proximal and distal, respectively, to a line connecting the medial and lateral boundaries of the dentate gyrus. In each region, neuronal profiles with a nucleus and nucleolus were mapped with the aid of a drawing tube within a rectangular grid $(500 \times 1000 \mu \mathrm{m})$ at a magnification of $200 \times(16 \times$ objective, $10 \times$ eyepiece, and $1.25 \times$ tube factor $)$, and the cells were subsequently counted. Cell counts were made in 2 sections ( $30 \mu \mathrm{m}$ thick) from each specimen, and the density of neurons per unit volume was calculated. The relationships between the dynorphin scores and neuronal densities for the 3 hippocampal regions were analyzed by Student's $t$-tests.

\section{Results}

\section{Control specimens}

Dynorphin A localization. In control specimens of human hippocampal formation, Dyn-IR structures were present within the polymorph or hilar region, extended throughout the CA3 field and ended at the border of CA2 (Fig. $2 A$ ). The density of immunoreactive structures was highest in the polymorph layer, where reaction product was present in relatively large punctate structures that were concentrated near the cell bodies and proximal dendrites of certain neurons (Fig. $2 A-C$ ). Many of these neurons were presumed to be mossy cells that are contacted by numerous mossy fiber terminals (Amaral, 1978; Claiborne et al., 1986; Scharfman and Schwartzkroin, 1988). Immunoreactive punctate structures of smaller diameter were evenly distributed throughout the pyramidal cell and proximal dendritic regions of most of the CA3 field (Fig. $2 A$ ). However, in the distal part of the field, reaction product was concentrated just above the pyramidal cell bodies and gradually tapered to an end at the junction between CA3 and CA2 (Fig. 2A). Virtually no specific reaction product was observed within the inner molecular layer of the dentate gyrus (Fig. 2, $A, C$ ), although, occasionally, a few labeled processes and somata were present within the granule cell layer. Such structures were most numerous at the angles of the dentate gyrus.

Timm's staining. The pattern of Timm's staining in control autopsy specimens from the human hippocampal formation was very similar to that of dynorphin A localization (cf. Figs. $1 B$ and $2 A$ ) and virtually identical to that described by Cassell and Brown (1984). Staining was most dense in the polymorph zone, where it was concentrated around many neurons (Fig. 1B). Stained elements were evenly distributed throughout CA3 and, as with dynorphin localization, frequently ended in an angle at the junction of $\mathrm{CA} 3$ and $\mathrm{CA} 2$ (Fig. $1 B$ ). In most regions, the granule cell and molecular layers were virtually free of stained 

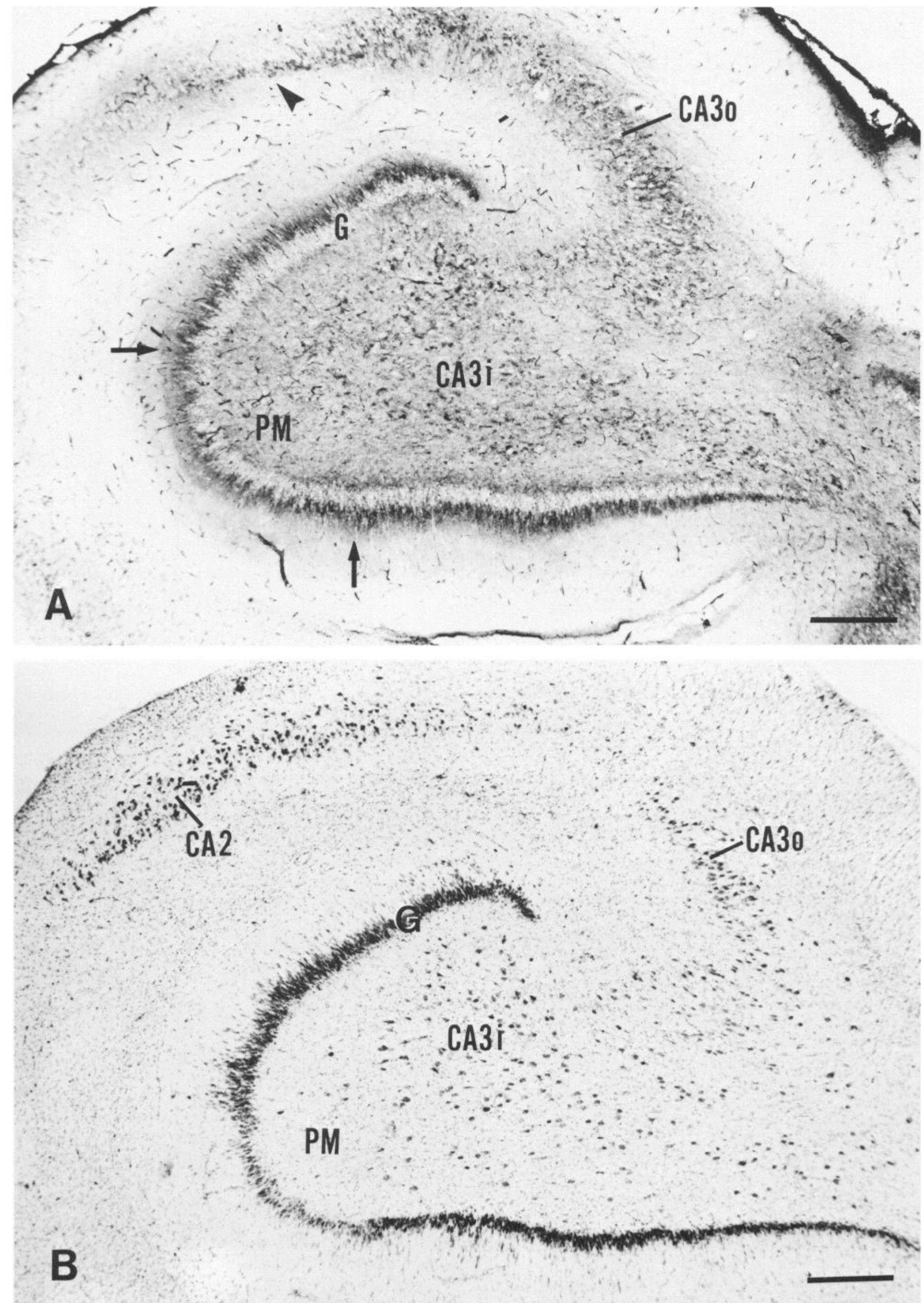

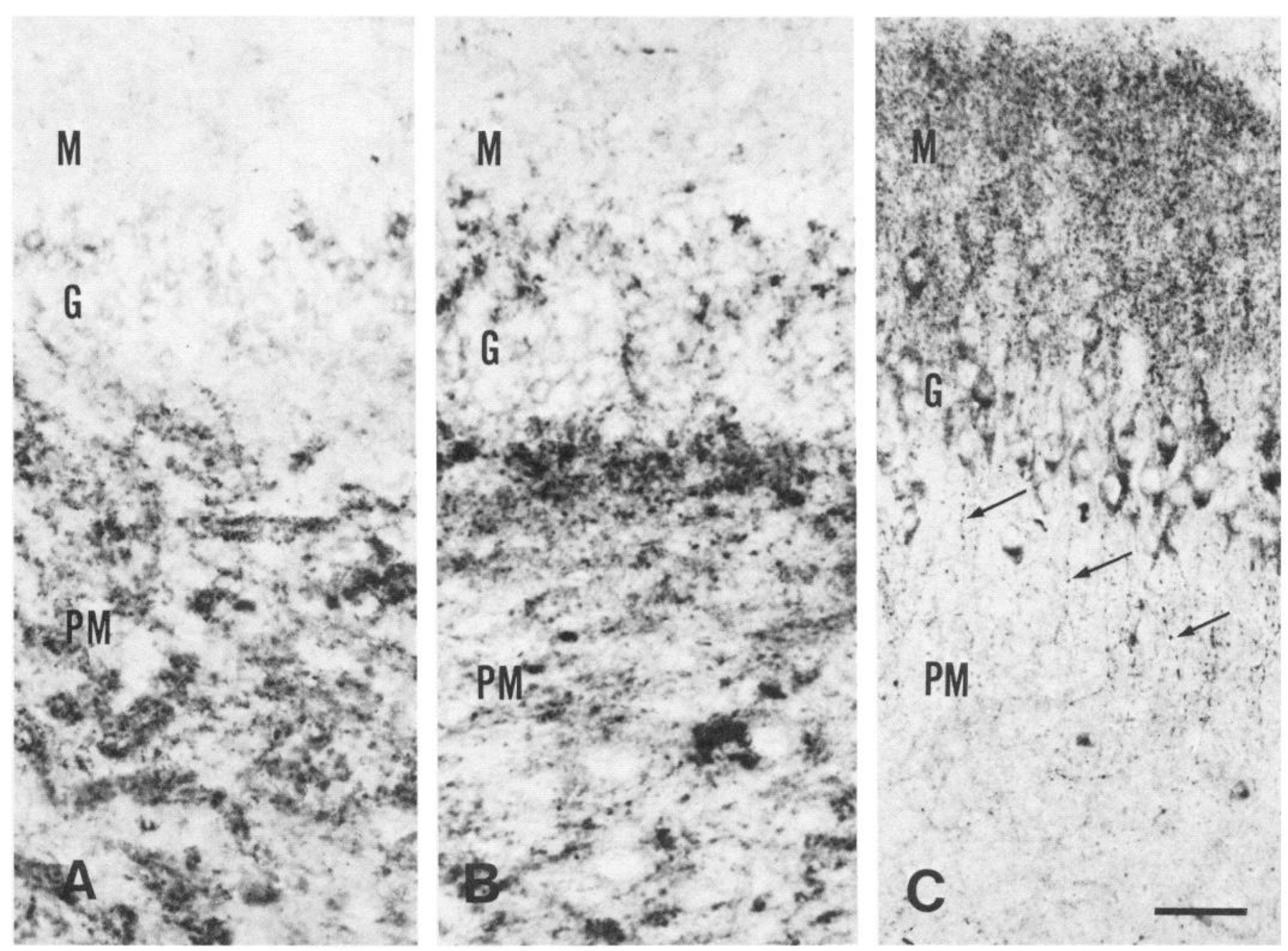

Figure 5. Comparison of dynorphin immunoreactivity in specimens from a control case $(A)$ and 2 patients with epilepsy $(B, C)$. $A$, In this control specimen, Dyn-IR is concentrated in the polymorph $(P M)$ region. Except for light staining of some granule cell somata, very little reaction product is evident in the granule cell $(G)$ or inner molecular $(M)$ layers. $B$, In this surgical specimen from an epileptic patient, Dyn-IR is present within the polymorph $(P M)$ region and is also evident in the granule cell $(G)$ layer, where it is concentrated at the border of the molecular $(M)$ layer. $C$, In another surgical specimen, a dense band of reaction product is present in the inner molecular $(M)$ layer, and increased labeling is also evident in the somata of many granule cells. Labeled fibers with periodic varicosities (arrows), which appear to be axons or axon collaterals of the granule cells, extend into the hilus. Reaction product is severely depleted in the polymorph $(P M)$ region. Scale bar, for all panels, $50 \mu \mathrm{m}$.

elements (Figs. 1B, 8A). However, stained fibers were occasionally present within the granule cell layer, particularly at the angles of the dentate gyrus. Likewise, penetration of the granule cell layer by Timm's stained fibers was more common at the rostral, enclosed, end of the dentate gyrus than in the central part of the hippocampal formation. Extensive staining in the inner segment of the molecular layer was not observed in any of the control specimens of this study.

\section{TLE surgical specimens}

Dynorphin A localization. In each of the surgically resected hippocampal specimens, Dyn-IR structures were present in the molecular and granule cell layers. In 7 of 10 cases, a distinct, darkly stained band of Dyn-IR elements was present in the inner portion of the molecular layer (Dynorphin score $=3$ ) (Figs. $3 \mathrm{~A}$, $4 A, 5 C$ ) and extended throughout the medial-lateral extent of the dentate gyrus (Figs. 3, 4). The average width of the band was $145 \pm 48 \mu \mathrm{m}$, and the staining typically occupied $28.7 \pm$ $5.3 \%$ of the molecular layer (Figs. $3 A, 4 A, 5 C$ ). In 4 of the 7 TLE specimens, the inner portion of the band was more densely stained than the outer part, while in the other 3 cases, the density of staining was relatively constant throughout the lamina. Immunoreactive elements within the band were small and punctate in form, thus suggesting labeling of axon terminals (Fig. $6 A$ ).

\footnotetext{
Figure 4. Dynorphin immunoreactivity and cresyl violet staining of adjacent coronal sections from the hippocampal formation of another patient with hippocampal epilepsy. $A$, A densely stained band of Dyn-IR structures (arrows) is present in the supragranular region of the molecular layer. Relatively low densities of staining are evident in the polymorph $(P M)$ region where there is significant cell loss (see $B$ ). However, reaction product is present in regions of retained neurons in the CA3 field and ends at the approximate border of the CA3 and CA2 fields (arrowhead). $B$, In a cresyl violet-stained section, neurons in the granule cell $(G)$ layer and CA2 field are relatively well preserved, whereas neurons in the polymorph $(P M)$ layer are severely depleted. Note the greater preservation of neurons in CA3i of this specimen than in that of Figure $3 B$. Scale bars, $500 \mu \mathrm{m}$.
} 


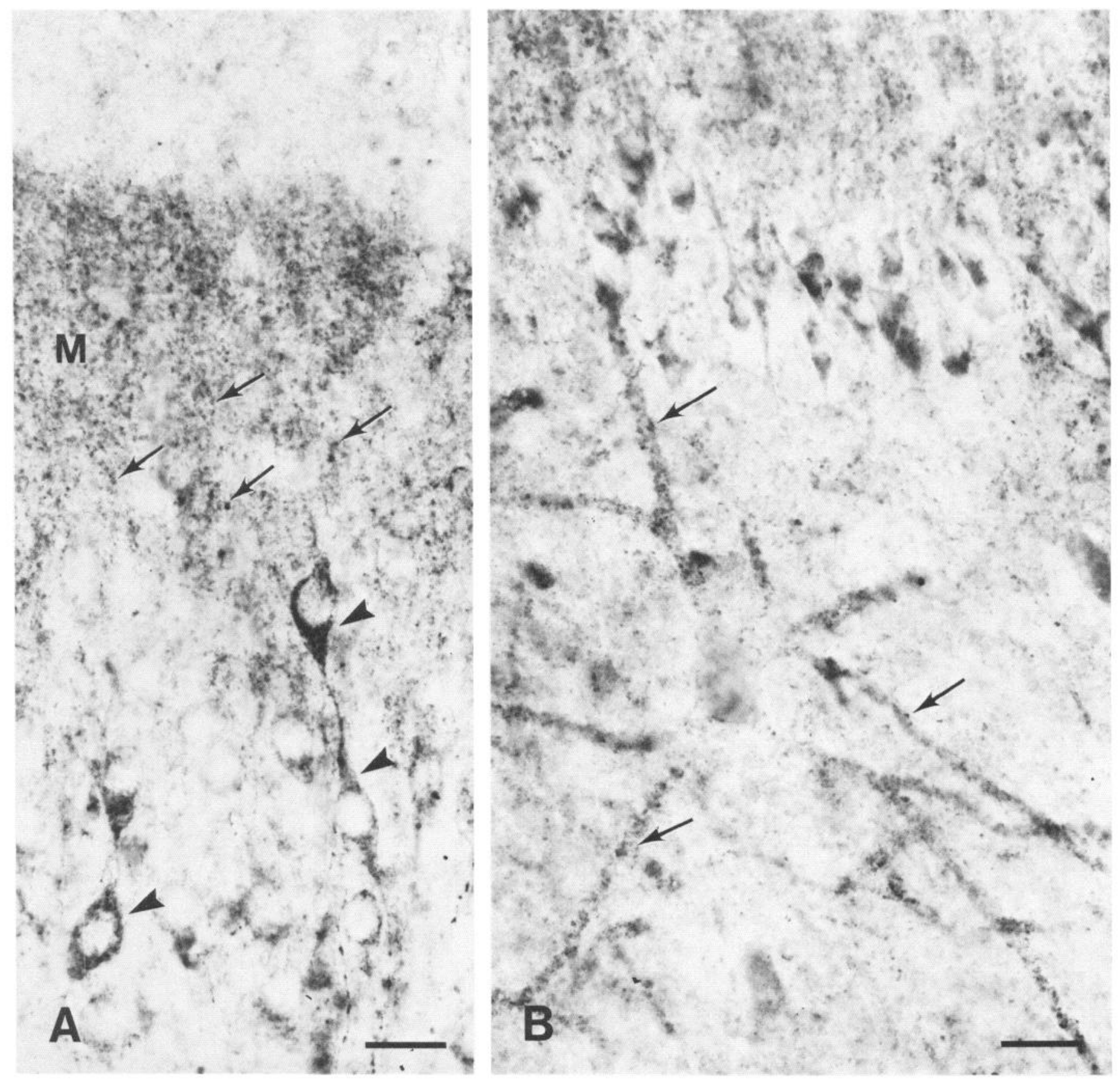

Figure 6. Dynorphin immunoreactivity in the dentate gyrus of surgical specimens from patients with hippocampal epilepsy. A, High concentrations of immunoreactive punctate structures (arrows), suggestive of axon terminals, are present in the inner molecular $(M)$ layer. Reaction product is also present in the somata of some granule cells (arrowheads). B, Reaction product is present along the dendrites (arrows) of a large neuron remaining in the polymorph layer. Scale bars, $25 \mu \mathrm{m}$.

Reaction product was frequently present in granule cell somata of the surgical specimens (Figs. $5 \mathrm{C}, 6 \mathrm{~A}$ ) and, occasionally, could be detected in the proximal segments of granule cell axons (Fig. $5 C$ ). In one additional case, a light band of supragranular staining, which was similar in other respects to the darker bands just described, was present in the inner molecular layer (Dynorphin score $=2$ ) $($ Fig. $7 B$ ). In specimens from the 2 remaining TLE cases, aberrant Dyn-IR elements were present in the granule cell and molecular layers but were less numerous than in the previous cases (Dynorphin score $=1$ ). The stained elements were most highly concentrated in the outer part of the granule cell layer (Fig. $5 B$ ), although a few immunoreactive fibers were scattered throughout the inner third of the molecular layer.

The patterns of dynorphin immunoreactivity in the polymorph and CA3 regions also differed between the TLE and control specimens. In cases with marked cell loss in these regions, dynorphin labeling was also greatly reduced (Figs. $3 A$, $5 C, 7 A$ ). Even in specimens with less severe cell loss in the CA3 field (Fig. $4 B$ ), there was often substantial cell loss in the polymorph region, and the relatively high concentration of reaction product in this region was no longer evident (compare Figs. $2 A$ and $4 A$ ). However, some immunoreactive elements were located 

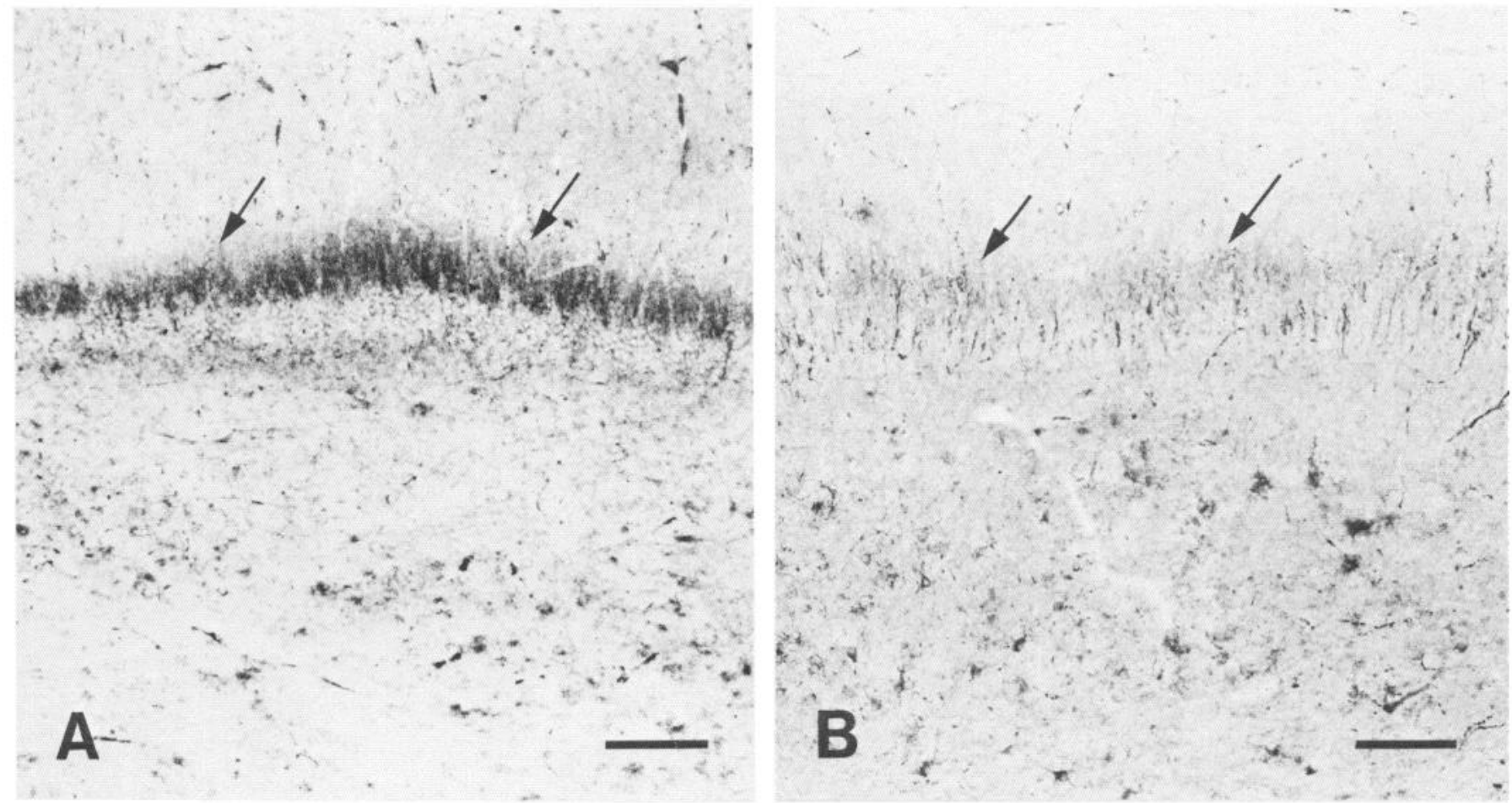

Figure 7. Comparison of dynorphin immunoreactivity in the dentate gyrus of 2 patients with hippocampal epilepsy. $A$, A densely stained band (arrows) is present in the inner molecular layer of this specimen, and such staining was characteristic of the majority of surgical specimens in this study. $B$, A similar, though lightly stained band (arrows) is present in this specimen from a patient who had experienced multiple seizures within the $24 \mathrm{hr}$ prior to surgery. Scale bars, $200 \mu \mathrm{m}$.

in close proximity to neurons that remained in these regions and were most frequently observed along their dendritic processes (Fig. 6B). Furthermore, a few of the neurons remaining in the hilus and CA3 regions exhibited dynorphin-like immunoreactivity within their cytoplasm. In this group of surgical specimens, some variations in the staining patterns at the most distal part of the CA3 field were also observed. In most cases, the staining appeared to end at the border between $\mathrm{CA} 3$ and CA2 (Fig. 4A), as in the control specimens. However, in 3 TLE cases, staining appeared to extend into the CA2 field (Fig. $3 A$ ). In the second group of TLE specimens with mild to moderate cell loss, a relatively normal pattern of dynorphin-like staining was present in the polymorph and CA3 fields (Fig. $5 B$ ), although there appeared to be fewer neuronal somata with high concentrations of Dyn-IR puncta around their cell bodies and proximal dendrites in the polymorph region.

Timm's staining. In 7 of the 10 TLE cases in which specimens were processed for dynorphin immunocytochemistry, blocks of hippocampal tissue were also processed for Timm's staining, and the results closely paralleled those of dynorphin localization. All cases that showed a band of dynorphin staining also exhibited a lamina of Timm's staining throughout the inner one-third to one-fourth of the molecular layer (Fig. $8 \mathrm{C}$ ). In these specimens, relatively low amounts of staining were evident in the polymorph and $\mathrm{CA} 3$ regions (Fig. $8 \mathrm{C}$ ), and the limited staining appeared to be related to marked cell loss in these regions. Thus, the patterns of staining in the Timm's and dynorphin-stained preparations were remarkably similar (cf. Figs. $5 C$ and $8 C$ ). In 2 cases, with only small numbers of Dyn-IR elements in the inner molecular layer, the Timm's staining was also confined primarily to the granule cell and immediately adjacent supra- granular region (Fig. $8 B$ ). In the latter 2 cases, the aberrant Timm's staining in the supragranular region appeared slightly more extensive than the dynorphin staining. However, in both cases, the Timm's stained specimens were obtained from more rostral regions of the hippocampal formation, where the dentate gyrus becomes enclosed and where specimens from control cases also show varying degrees of Timm's staining within the granule cell layer. Thus, it was more difficult to evaluate the significance of increased staining within the granule cell and innermost molecular layer in these regions. In these cases, substantial Timm's staining was present within the hilus and $\mathrm{CA} 3$ regions (Fig. $8 B$ ), where there was less cell loss than in the previous cases.

Neuronal loss. The density of neurons in the control and TLE surgical specimens differed significantly for each of the hippocampal regions analyzed (Table 1). In 8 of the 10 TLE surgical specimens, there was marked neuronal loss in the hippocampal fields, whereas, in 2 cases, the cell loss was more moderate.

Table 1. Comparison of neuronal densities in control and surgical specimens.

\begin{tabular}{|c|c|c|c|c|}
\hline \multirow{2}{*}{$\begin{array}{l}\text { Hippo- } \\
\text { campal } \\
\text { region }\end{array}$} & \multicolumn{2}{|c|}{ Density (means \pm SEM) } & \multirow[b]{2}{*}{$\begin{array}{l}t \text { values } \\
(d f)^{a}\end{array}$} & \multirow[b]{2}{*}{$p$ values } \\
\hline & $\begin{array}{l}\text { Controls } \\
(n=6)\end{array}$ & $\begin{array}{l}\text { Patients } \\
(n=10)\end{array}$ & & \\
\hline PM & $92.7 \pm 3.4$ & $26.8 \pm 6.9$ & $7.1(14)$ & $<0.0001$ \\
\hline $\mathrm{CA} 3 \mathrm{i}$ & $114.6 \pm 4.2$ & $42.3 \pm 9.8$ & $5.5(14)$ & $<0.0001$ \\
\hline $\mathrm{CA} 3 \mathrm{o}$ & $166.2 \pm 5.3$ & $70.0 \pm 13.9$ & $5.4(13)$ & $<0.0001$ \\
\hline
\end{tabular}

Densities are expressed as neurons per sample region of $1.5 \times 10^{7} \mu \mathrm{m}^{3}$ in the polymorph (PM), CA3i, and CA3o regions.

${ }^{a}$ Student's $t$-test. 


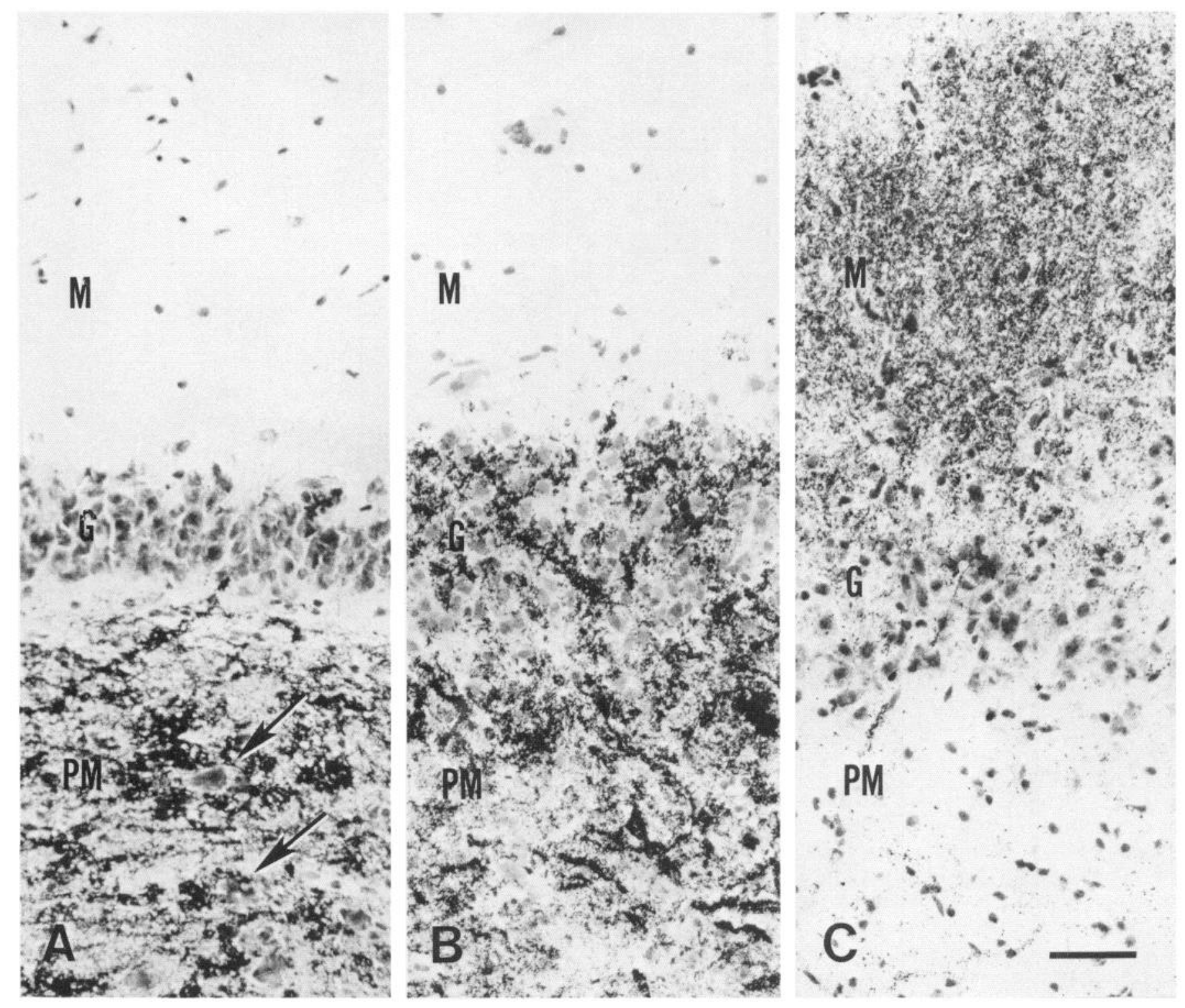

Figure 8. Comparison of Timm's staining in specimens from a control case $(A)$ and 2 patients with epilepsy $(B, C)$. $A$, In this control specimen, dense Timm's staining is present in the polymorph $(P M)$ layer, where it is frequently concentrated near some neuronal somata (arrows). Virtually no Timm's staining is present in the granule cell $(G)$ and molecular $(M)$ layers. All sections have been counterstained with cresyl violet. $B$, In a surgical specimen, Timm's staining extends from the polymorph $(P M)$ region into the granule cell $(G)$ layer. Only a few stained elements are present in the molecular $(M)$ layer. $C$, In another surgical specimen, Timm's staining is concentrated in the inner molecular $(M)$ layer. Very little staining is present in the polymorph $(P M)$ region, where there is substantial neuronal loss. Scale bar, for all panels, $50 \mu \mathrm{m}$.

Table 2. Relationship of dynorphin scores to neuronal densities

\begin{tabular}{|c|c|c|c|c|c|}
\hline \multirow{3}{*}{$\begin{array}{l}\text { Hippo- } \\
\text { campal } \\
\text { region }\end{array}$} & \multicolumn{3}{|c|}{ Neuronal density (mean \pm SEM) } & \multirow{2}{*}{\multicolumn{2}{|c|}{ Score 0 vs 3}} \\
\hline & \multirow{2}{*}{$\begin{array}{l}\text { Score } 0 \\
(n=6) \\
\end{array}$} & \multirow{2}{*}{$\begin{array}{l}\text { Score 1 } \\
(n=2)\end{array}$} & \multirow{2}{*}{$\begin{array}{l}\text { Score } 3 \\
(n=7)\end{array}$} & & \\
\hline & & & & $t$ value $^{a}$ & $p$ value \\
\hline PM & $92.7 \pm 3.4$ & $65.8 \pm 2.8$ & $15.5 \pm 2.6$ & 18.3 & $<0.0001$ \\
\hline $\mathrm{CA} 3 \mathrm{i}$ & $114.6 \pm 4.2$ & $89.0 \pm 20.5$ & $27.9 \pm 6.6$ & 10.6 & $<0.0001$ \\
\hline CA3o & $166.2 \pm 5.3$ & $122.5--^{b}$ & $68.2 \pm 15.1$ & 5.7 & $<0.0001$ \\
\hline
\end{tabular}

Extent of dynorphin immunoreactivity in the supragranular region is indicated by scores of 0 (absent), 1 (limited), and 3 (marked). Neuronal densities are expressed as neurons per sample region $\left(1.5 \times 10^{7} \mu \mathrm{m}^{3}\right)$ in the polymorph and inner and outer CA3 regions.

${ }^{a}$ Student's $t$-test (each 11 degrees of freedom).

${ }^{b}$ Region available for cell counts in only 1 case. 
Additional analyses were conducted to determine the relationships between the dynorphin scores and density of neurons in each region. Student's $t$-tests indicated that neuronal densities in the groups with dynorphin scores of 0 and 3 were significantly different in each of the 3 regions (Table 2). Comparisons of the percentage cell loss in the 3 regions of cases with dynorphin scores of 3 indicated that the cell loss was greatest in the polymorph region (polymorph, $-83 \%$; CA3i, $-76 \%$; CA3o, $-59 \%$ ). The number of cases with dynorphin scores of 1 and $2(n=2$ and $n=1$, respectively) were considered too small for statistical analysis, but the data from these cases are displayed graphically in Figure 9. Neuronal densities in the 2 cases with dynorphin scores of 1 were clearly different from those with dynorphin scores of 0 and 3 , particularly in the polymorph region, where there was no overlap of data points for the 3 groups. Thus, cases with dynorphin scorcs of 1 appcarcd to bc an intermediate group in the amount of cell loss as well as the extent of supragranular dynorphin staining. In contrast, the neuronal densities of the single case with a dynorphin score of 2 did not appear to differ from those of the group with dynorphin scores of 3 (Fig. 9).

Dispersion of granule cell somata. In addition to varying degrees of cell loss within the hippocampal formation, a second frequently observed morphological alteration in the TLE specimens was dispersion of the granule cell somata with a resulting increase in the width of the granule cell layer and lower densities of neurons in this layer (Fig. 10). Such granule cell dispersion was observed in 8 of the 10 TLE cases and in each of the specimens with a band of Dyn-IR structures in the inner molecular layer. The dispersion occurred in TLE cases with and without observable granule cell loss.

History. Febrile seizures in infancy and early childhood were the most consistent feature in the history of patients with extensive dynorphin staining in the inner molecular layer. Six of the 8 patients with a band of Dyn-IR elements ( 7 darkly and 1 lightly stained band) had experienced febrile seizures or meningitis- and encephalitis-associated seizures within the first 3 years of life, whereas neither of the 2 patients with more limited dynorphin-like immunoreactivity in the supragranular layer had such a history. The patients' clinical histories and histological findings are summarized in Table 3.

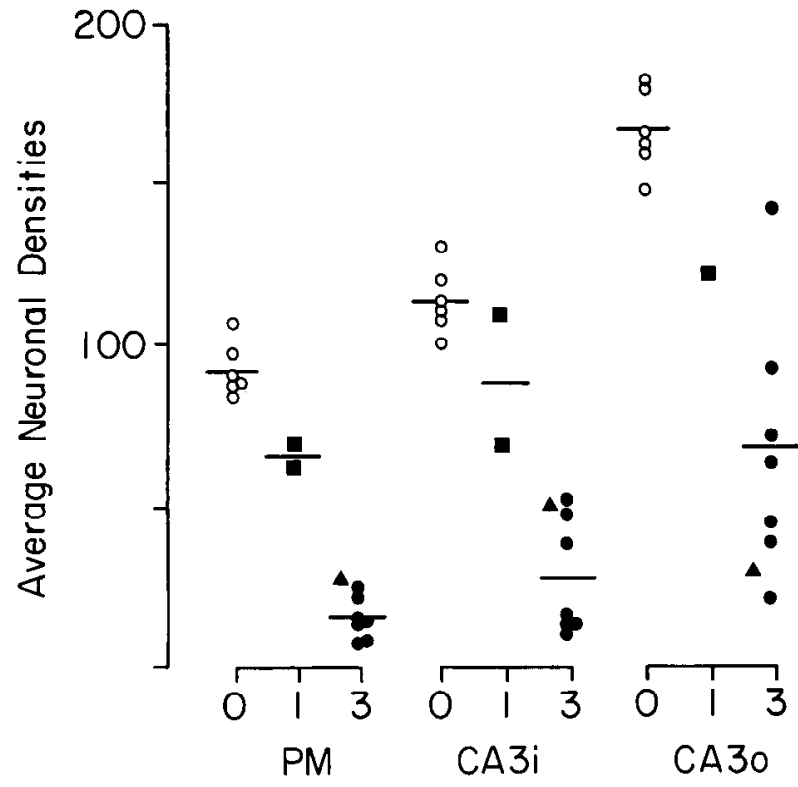

Figure 9. Relationship of dynorphin scores to neuronal densities (neurons $/ 1.5 \times 10^{7} \mu \mathrm{m}^{3}$ ) in 3 hippocampal regions. Dynorphin scores indicate the relative amounts of Dyn-IR structures in the inner molecular layer: $0=$ absent $(0) ; 1=$ limited $(\square) ; 3=$ marked (0). Horizontal lines indicate the mean for each group. Data from the single case with a dynorphin score of 2 (lightly stained band in inner molecular layer) are indicated by triangles $(\Delta)$, placed near the data points for dynorphin scores of 3 . These data are not included in the statistical computations.

\section{Discussion}

Supragranular localization of both dynorphin-like immunoreactivity and Timm's staining in surgical specimens of the present study suggests that reorganization of mossy fibers has occurred in patients with TLE of the hippocampal type. Furthermore, the presence of such labeling in all TLE specimens examined indicates that morphological reorganization of the mossy fibers may occur frequently in patients with severe hippocampal epilepsy. This suggestion is consistent with preliminary reports of supragranular Timm's staining in surgical spec-

Table 3. Summary of patient histories and neuroanatomical findings

\begin{tabular}{|c|c|c|c|c|c|c|c|c|}
\hline $\begin{array}{l}\text { Case } \\
\text { no. }\end{array}$ & $\begin{array}{l}\text { Age } \\
(\mathrm{yr})\end{array}$ & Sex & $\begin{array}{l}\text { Age at } \\
\text { onset } \\
(\mathrm{yr})\end{array}$ & $\begin{array}{l}\text { Febrile seizure or other early } \\
\text { risk factors }\end{array}$ & $\begin{array}{l}\text { Seizure within } \\
48 \mathrm{hr} \text { prior to } \\
\text { surgery }\end{array}$ & Dyn-IR & $\begin{array}{l}\text { Cell loss } \\
\text { in PM or } \\
\text { CA3 zones }\end{array}$ & $\begin{array}{l}\text { Granule } \\
\text { cell } \\
\text { dispersion } \\
\end{array}$ \\
\hline 1 & 36 & $\mathrm{~F}$ & 8 & - & - & 3 & +++ & + \\
\hline 2 & 32 & $\mathbf{M}$ & 20 & Febrile seizure $-3 \mathrm{mo}$ & - & 3 & +++ & + \\
\hline 3 & 29 & $\mathrm{~F}$ & 7 & Febrile seizure with respiratory arrest $-18 \mathrm{mo}$ & - & 3 & +++ & + \\
\hline 4 & 20 & $\mathbf{M}$ & 8 & - & - & 3 & +++ & + \\
\hline 5 & 39 & $\mathbf{M}$ & 23 & Head injury with loss of consciousness $-3 \mathrm{yr}$ & - & 1 & ++ & - \\
\hline 6 & 36 & $\mathbf{M}$ & 10 & Febrile seizure -1 yr & + & 2 & +++ & + \\
\hline 7 & 30 & $\mathbf{F}$ & 11 & Febrile seizure $-1 \mathrm{yr}$ & + (small) & 3 & $1+1$ & t \\
\hline 8 & 19 & $\mathbf{M}$ & 1.5 & $\begin{array}{l}\text { Prolonged labor with forceps delivery; } \\
\text { meningitis, seizure }-10 \text { mo }\end{array}$ & - & 3 & +++ & + \\
\hline 9 & 27 & $\mathbf{M}$ & 13 & Forceps delivery; twin gestation & + & 1 & ++ & - \\
\hline 10 & 24 & $\mathbf{M}$ & 3 & Viral encephalitis with coma, seizure $-3 \mathrm{yr}$ & + & 3 & +++ & + \\
\hline
\end{tabular}

+++ , marked cell loss; ++ , mild to moderate cell loss; + , present; - , absent.

Summary of Dyn-IR scale (see text for detailed description): $3=$ dense band in inner molecular layer, $2=$ light band in inner molecular layer, $1=$ immunoreactive elements confined primarily to granule cell layer. 


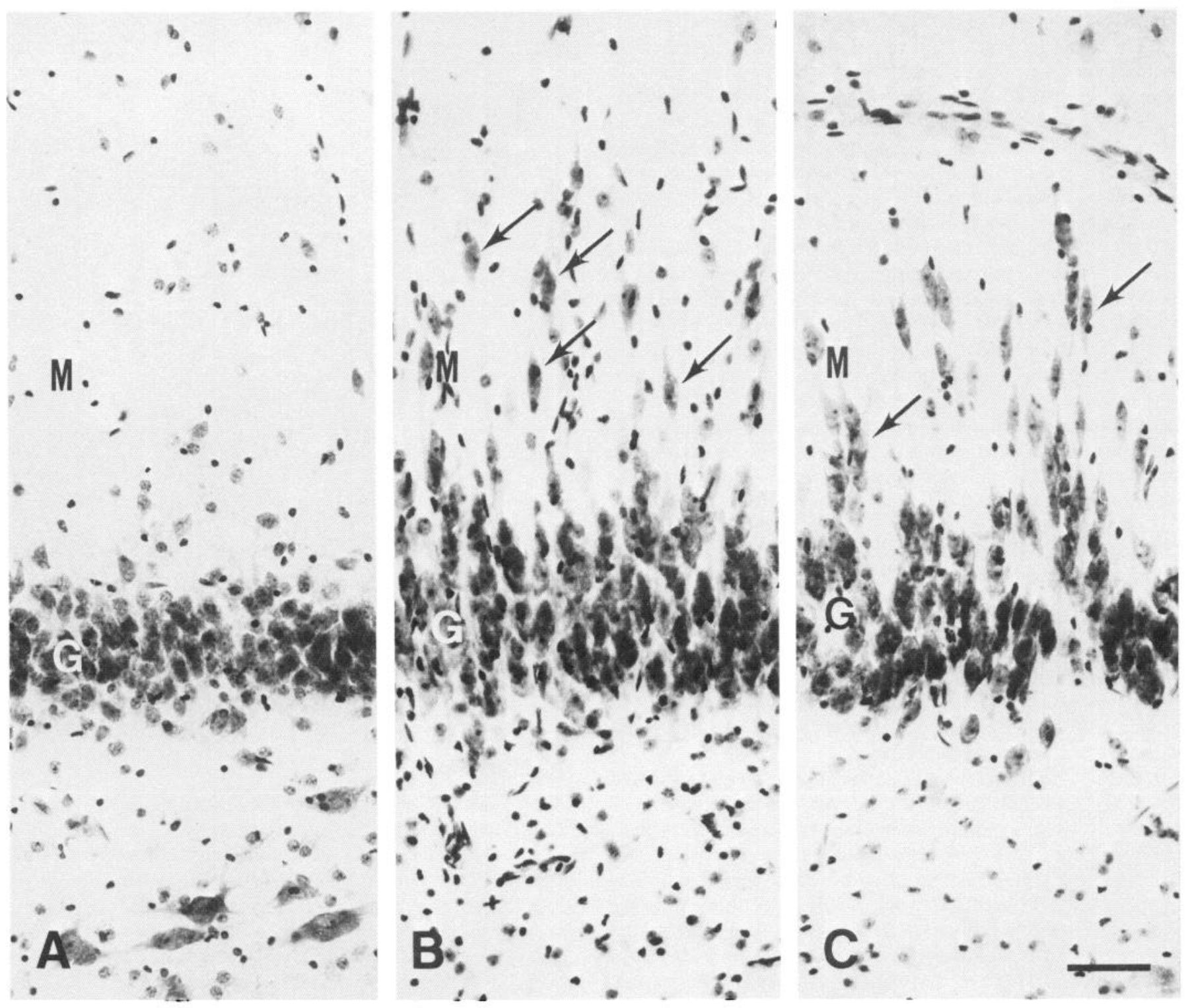

Figure 10. Comparison of the distribution of granule cells in cresyl violet-stained sections from a control case $(A)$ and patients with hippocampal epilepsy $(B, C)$. A, In this control specimen, the granule cell somata form a compact layer $(G)$ with relatively even upper and lower borders. A few scattered neurons are evident in the molecular layer $(M)$, but most do not resemble granule cells and may be local circuit neurons. $B$, In this surgical specimen, the granule cells appear more dispersed than in control specimens, and many neurons resembling granule cells (arrows) are present in the molecular layer $(M)$. C, In another surgical specimen, the upper border of the granule cell layer $(G)$ is not clearly defined, and some presumptive granule cells in the molecular layer $(M)$ appear to be aligned in columns (arrows). Scale bar, for all panels, $50 \mu \mathrm{m}$.

imens from patients with TLE by 2 other groups of investigators (Babb et al., 1988a, b; Cascino et al., 1988).

Since the extent of aberrant staining varied among the cases, we considered neuroanatomical and clinical findings that might be associated with the different patterns. First, the amount of cell loss clearly differed in TLE specimens showing the 2 major patterns of dynorphin staining. All TLE specimens in this study had some cell loss within the hippocampal formation, but this cell loss was most severe in the group with extensive dynorphin staining in the inner molecular layer, whereas it was more moderate in the 2 specimens with limited supragranular labeling. In both groups, cell loss was greatest in the polymorph region. These findings are very similar to those of experimental studies in rats, in which supragranular Timm's staining was associated with loss of neurons in the CA4 region (Zimmer, 1973, 1974;
Nadler et al., 1980; Laurberg and Zimmer, 1981); and the extent of supragranular staining was correlated with the severity of cell loss in CA4 (Tauck and Nadler, 1985).

The question of whether cell loss is necessary for stimulation of mossy fiber sprouting cannot be addressed in the present study since all specimens had some hippocampal cell loss. However, Babb et al. (1988a, b) found that supragranular Timm's staining occurred only in cases with neuronal loss in the hippocampus and that the density of Timm's staining was significantly correlated with a loss of pyramidal neurons in $\mathrm{CA} 3$, although there was a trend toward correlation with a loss of neurons in CA4. In contrast, Cascino et al. (1988) found Timm's stained elements in the supragranular regions of patients with no overt cell loss in the hippocampus, as well as patients with the typical patterns of cell loss associated with hippocampal sclerosis. Likewise, 
Represa et al. (1989b) found an increase of kainic acid binding, thought to be associated with mossy fiber terminals, in the supragranular region of children with epilepsy of several different types who showed no histological evidence of hippocampal lesions.

Despite the apparent relationship between the extent of cell loss and mossy fiber sprouting in the present study, there are 2 important reasons for caution in interpreting these findings. First, it is generally impossible to examine the entire hippocampal formation in surgical TLE specimens and, while little neuronal loss may be evident in one coronally sectioned block of tissue, greater cell loss may be present at another rostral-caudal level. Such loss could provide the stimulus for mossy fiber reorganization at distant levels of the hippocampal formation since experimental findings in rats indicate that neurons in the hilar region project to granule cells at different rostral-caudal levels of the dentate gyrus (Zimmer, 1971; Fricke and Cowan, 1978; Swanson et al., 1978; Laurberg, 1979; Amaral and Insausti, 1989). Second, it is possible that mossy fiber sprouting is related to loss of a particular class of neurons that innervates the inner molecular layer, and that even a small loss of neurons, provided they were of this type, could provide a potent stimulus for mossy fiber sprouting. One particularly good candidate for such neurons is the mossy cell that normally receives a large input from mossy fibers (Amaral, 1978; Ribak et al., 1985; Claiborne et al., 1986). Since most of these neurons are located in the polymorph layer (Scharfman and Schwartzkroin, 1988; Amaral and Insausti, 1989), it is likely that many of them were lost in the specimens examined in the present study. Loss of mossy cells could provide a particularly strong stimulus for mossy fiber reorganization since it would remove a major target of the mossy fibers and their collaterals and, simultaneously, produce substantial deafferentation of the inner zone of the molecular layer (Amaral and Campbell, 1986). Previous studies in experimental animals have suggested that deafferentation is the more effective stimulus for mossy fiber sprouting (Laurberg and Zimmer, 1981), but the combined effects of loss of a target structure and the creation of vacant synaptic sites through deafferentation might be especially potent. deLanerolle et al. (1988) have also suggested that a loss of hilar mossy cells occurs in human surgical specimens with typical hippocampal sclerosis and have described an anomalous neuropeptide $Y$-positive plexus in the inner molecular layer of these patients. The investigators suggest that the loss of mossy cell terminals in the inner molecular layer leads to growth of neuropeptide $Y$-positive fibers into this region. Thus, it appears that reorganization of several neurochemically defined systems may occur in hippocampal epilepsy, and it will be important to determine the physiological effects of each of these systems and their relative influence in the production of epileptiform activity.

A second neuroanatomical difference between specimens with extensive and more limited supragranular labeling was the presence of granule cell dispersion. Each TLE specimen with extensive staining in the inner molecular layer had substantial granule cell dispersion, whereas the 2 cases with more limited supragranular staining showed a normal pattern of granule cell alignment. No description of granule cell dispersion has been found in previous studies of experimental animals or human tissue, and a more detailed analysis of this phenomenon is in progress. There are several reasons to suspect that this alteration and extensive supragranular mossy fibers could be related. For example, the abnormal position of granule cells could lead to misalignment of both the afferent and efferent connections of these neurons, and, as a consequence, one might expect altered laminar patterns of numerous substances in the molecular layer of such tissue. Furthermore, the axons and axon collaterals of these neurons might be attracted to postsynaptic sites in the inner molecular layer. Indeed, Ramón y Cajal (1893) described some displaced granule cells in the molecular layer of the normal rabbit dentate gyrus and demonstrated that their axon collaterals were distributed within the inner molecular layer. The present pattern of granule cell dispersion might be viewed as an exaggeration of the small number of granule cells that are normally present in the molecular layer (Ramón y Cajal, 1893; Laurberg and Zimmer, 1981; McGinty et al., 1983), with a resultant increase in the number of mossy fiber axons that might be attracted to synaptic sites in the inner molecular layer. However, it is unlikely that mossy fibers of displaced granule cells were entirely responsible for the supragranular dynorphin and Timm's staining. Presumably, mossy fibers or their collaterals in the hilus and $\mathrm{CA} 3$ region also form recurrent projections that penetrate the granule cell layer and enter the inner molecular layer (Nadler et al., 1980; Laurberg and Zimmer, 1981).

A third difference between the cases with extensive and limited reorganization of the mossy fibers in TLE spccimens was the clinical characteristics of the seizures. All 8 patients with a band of Dyn-IR elements in the inner molecular layer had electroclinical signs consistent with predominant involvement of medial temporal lobe structures, i.e., hippocampus (Dreifuss et al., 1985). In contrast, the 2 patients with more limited supragranular staining had electroclinical signs indicating greater involvement of lateral than medial temporal lobe structures, as was confirmed by routine neuropathological studies. These observations were also consistent with greater hippocampal cell loss in the first group of patients.

This study has focused on alterations in the location of DynIR elements in TLE specimens, but previous studies of experimental seizure models suggest that the intensity of dynorphin immunoreactivity (Lason et al., 1983; Przewlocki et al., 1983; Iadarola et al., 1986; Kanamatsu et al., 1986a, b; Gall, 1988) and zinc labeling (Sloviter, 1985; Frcderickson ct al., 1988) can also vary according to the prior seizure history. In the present study, there was only one case in which prior seizure activity may have led to a detectable decrease in the intensity of staining in the inner molecular layer. The patient had experienced 2-3 complex partial seizures within the $48 \mathrm{hr}$ preceding surgery, and, while there were discernible bands of dynorphin immunoreactivity and Timm's staining in the inner molecular layer, they were more lightly labeled than in other TLE specimens. Other morphological features of the tissue were similar to those of patients with a dense band of dynorphin staining and included marked cell loss and dispersion of the granule cells. These observations are consistent with the suggestion that reorganized supragranular fibers were present in this patient and were activated during seizure activity, resulting in a sufficient release of dynorphin and zinc to reduce their content in the terminals, and, thus, lcad to reduced dynorphin and Timm's staining.

The functional significance of mossy fiber reorganization in the human hippocampal formation will depend, in large part, on the circuitry that is established. An electron microscopic study has provided evidence for synaptic contacts between reorganized mossy fiber terminals and granule cell dendrites in the rat (Frotscher and Zimmer, 1983). Since the mossy fibers are normally excitatory, a monosynaptic recurrent excitatory 
path is presumably created that could contribute to increased excitability and synchronous firing of the granule cells and, thus, facilitate seizures. Indeed, physiological and behavioral studies in kainic acid-treated rats favor this suggestion. Tauck and Nadler (1985), in extracellular studies of hippocampal slices, found that only slices from animals with clear evidence of recurrent mossy fiber collaterals showed multiple population spikes in the granule cell layer in response to hilar stimulation. In addition, Cronin and Dudek (1988) found that kainic acid-treated rats which exhibited chronic seizures had significantly more sprouting than treated animals which did not have seizures. These observations suggest that reorganized mossy fibers are functional but potentially maladaptive and may contribute to the initiation and propagation of seizure activity.

However, Timm's staining of mossy fibers in the supragranular region of human hippocampus is not pathognomonic of epilepsy for such staining has also been described by Cassell and Brown (1984) in 3 cases that were 72 years of age or older but had no known neurological disorders. Neuroanatomical changes and clinical events that might relate to the supragranular staining in these patients were not identified. We did not observe such staining in a 71-year-old control case. It is likely that in humans, as in experimental animals, different types of alterations in the afferent input to the hippocampal formation can stimulate mossy fiber sprouting. The functional result of such reorganization will depend on the entire synaptic circuitry of the region. Thus, it is critical to learn more about target cells and subsequent links in the pathway from the granule cells. In each of the TLE specimens examined, some neurons in the CA3 field that could provide the next link in the pathway were retained. These neurons appeared to receive a mossy fiber input, as indicated by the presence of dynorphin-like immunoreactivity and Timm's staining near their cell bodies and proximal dendrites. Furthermore, the presence of Dyn-IR structures within the CA2 field of some cases suggested that additional aberrant connections might exist.

The physiological effects of dynorphin in the putative reorganized circuit are now of particular interest. Dynorphin peptides are apparently relcased from mossy fiber terminals along with glutamate and modulate synaptic activity through pre- or postsynaptic mechanisms (Chavkin et al., 1983; Terrian et al., 1988), but both excitatory and inhibitory effects have been described in the CA3 region of the normal rat hippocampus (Gruol et al., 1983; Moises and Walker, 1985; Iwama et al., 1986). Thus, either pro- or anticonvulsant effects of dynorphin in the dentate gyrus could be postulated (Siggins et al., 1986; Tortella, 1988).

The fundamental finding of the present study is that morphological reorganization of the presynaptic components of a major neuronal pathway can occur in human epileptic tissue. Sprouting of hippocampal mossy fibers in humans, also suggested by the findings of several other groups of investigators (Babb et al., 1988b; Cascino et al., 1988; Represa et al., 1989b), supports an earlier hypothesis that there is neuronal plasticity of both axonal and dendritic elements in the cerebral cortex and hippocampus of patients with epilepsy (DeLorenzo and Glaser, 1981). Recently, alterations in the distribution of glutamate receptor ligands and markers of the cholinergic system have also been described in the hippocampal formation of patients with TLE (Geddes et al., 1987; Green, 1987). Considered together, these findings emphasize the need for more dynamic views of the functional circuitry of involved brain regions in epilepsy.
Some forms of epilepsy may result not only from deficits in the system, due to neuronal loss, but also from reorganization of connections between remaining neurons.

Note added in proof: Since this paper was accepted for publication, deLanerolle et al. (1989) and Sutula et al. (1989) have provided additional evidence for neuronal reorganization in human TLE.

\section{References}

Amaral, D. G. (1978) A Golgi study of cell types in the hilar region of the hippocampus in the rat. J. Comp. Neurol. 182: 851-914.

Amaral, D. G., and M. J. Campbell (1986) Transmitter systems in the primate dentate gyrus. Human Neurobiol. 5: 169-180.

Amaral, D. G., and R. Insausti (1989) The hippocampal formation. In The Human Nervous System, G. Paxinos, ed., Academic, New York (in press)

Amaral, D. G., R. Insausti, and M. J. Campbell (1988) Distribution of somatostatin immunoreactivity in the human dentate gyrus. $\mathrm{J}$. Neurosci. 8: 3306-3316.

Andersen, P., T. W. Blackstad, and T. Lömo (1966) Location and identification of excitatory synapses on hippocampal pyramidal cells. Exp. Brain Res. 1: 236-248.

Babb, T. L., W. J. Brown, J. Pretorius, C. Davenport, J. P. Lieb, and P. H. Crandall (1984) Temporal lobe volumetric cell densities in temporal lobe epilepsy. Epilepsia 25: 729-740.

Babb, T. L., W. R. Kupfer, and J. K. Pretorius (1988a) Recurrent excitatory circuits by "sprouted" mossy fibers into the fascia dentata of human hippocampal epilepsy. Epilepsia 29:674.

Babb, T. L., W. R. Kupfer, and J. K. Pretorius (1988b) Synaptic reorganization of mossy fibers into inner molecular layer in human epileptic fascia dentata. Soc. Neurosci. Abstr. 14: 881

Barber, R. P., J. E. Vaughn, R. E. Wimer, and C. C. Wimer (1974) Genetically-associated variations in the distribution of dentate granule cell synapses upon the pyramidal cell dendrites in mouse hippocampus. J. Comp. Neurol. 156: 417-434.

Ben-Ari, Y. (1985) Limbic seizure and brain damage produced by kainic acid: Mechanisms and relevance to human temporal lobe epilepsy. Neuroscience 14: 375-403.

Bruton, C. J. (1988) The Neuropathology of Temporal Lobe Epilepsy, Oxford, London.

Cascino, G., T. Sutula, J. Cavazos, I. Parada, and L. Ramirez (1988) Hippocampal mossy fiber synaptic reorganization in intractable partial epilepsy: A clinicopathologic study. Epilepsia 29: 684.

Cassell, M. D., and M. W. Brown (1984) The distribution of Timm's stain in the nonsulphide-perfused human hippocampal formation. J. Comp. Neurol. 222: 461-471.

Chavkin, C., C. Bakhit, E. Weber, and F. E. Bloom (1983) Relative contents and concomitant release of prodynorphin/neoendorphin-derived peptides in rat hippocampus. Proc. Natl. Acad. Sci. USA 80: 7669-7673.

Christensson-Nylander, I., and L. Terenius (1985) Dynorphin peptides in human substantia nigra. Neuropeptides 6: 391-396.

Claiborne, B. J., D. G. Amaral, and W. M. Cowan (1986) A light and electron microscopic analysis of the mossy fibers of the rat dentate gyrus. J. Comp. Neurol. 246: 435-458.

Cotman, C. W., and J. V. Nadler (1978) Reactive synaptogenesis in the hippocampus. In Neuronal Plasticity, C. W. Cotman, ed., pp. 227271, Raven, New York.

Cronin, J., and F. E. Dudek (1988) Chronic seizures and collatcral sprouting of dentate mossy fibers after kainic acid treatment in rats. Brain Res. 474: 181-184.

Danscher, G., and J. Zimmer (1978) An improved Timm sulphide silver method for light and electron microscopic localization of heavy metals in biological tissues. Histochemistry 55: 27-40.

deLanerolle, N. C., R. S. Sloviter, J. Kim, R. Robbins, and D. D. Spencer (1988) Evidence for hippocampal interneuron loss in human temporal lobe epilepsy. Epilepsia 29: 674.

deLanerolle, N. C., J. H. Kim, R. J. Robbins, and D. D. Spencer (1989) Hippocampal interneuron loss and plasticity in human temporal lobe epilepsy. Brain Res. 495: 387-395.

DeLorenzo, R. J., and G. H. Glaser (1981) Neuropathologic changes and neuronal plasticity in temporal lobe-limbic epilepsy. Neurology 31: 114. 
Dreifuss, F. E., M. Martinez-Lage, J. Roger, M. Seino, P. Wolf, and M. Dam (1985) Proposal for classification of epilepsies and epileptic syndromes. Epilepsia 26:268-278.

Elliott, K. A. C. (1984) The use of brain slices. In Handbook of Neurochemistry, Vol. 2, A. Lajtha, ed., pp. 103-114, Plenum, New York.

Frederickson, C. J., M. A. Klitenick, W. I. Manton, and J. B. Kirkpatrick (1983) Cytoarchitectonic distribution of zinc in the hippocampus of man and the rat. Brain Res. 273: 335-339.

Frederickson, C. J., M. D. Hernandez, S. A. Goik, J. D. Morton, and J. F. McGinty (1988) Loss of zinc staining from hippocampal mossy fibers during kainic acid induced seizures: A histofluorescence study. Brain Res. 446: 383-386.

Fricke, R., and W. M. Cowan (1978) An autoradiographic study of the commissural and ipsilateral hippocampo-dentate projections in the adult rat. J. Comp. Neurol. 181: 253-270.

Frotscher, M., and J. Zimmer (1983) Lesion-induced mossy fibers to the molecular layer of the rat fascia dentata: Identification of postsynaptic granule cells by the Golgi-EM technique. J. Comp. Neurol. 215: 299-311.

Gall, C. (1988) Seizures induce dramatic and distinctly different changes in enkephalin, dynorphin, and CCK immunoreactivities in mouse hippocampal mossy fibers. J. Neurosci. 8: 1852-1862.

Geddes, J. W., D. T. Monaghan, L. D. Cahan, B. H. Choi, and C. W. Cotman (1987) Alterations in excitatory amino acid receptors in temporal lobe epilepsy. Epilepsia 28: 600 .

Green, R. C. (1987) Altered cholinergic fiber architecture and selective survival of AChE-positive hilar neurons with hippocampal sclerosis in human temporal lobe epilepsy. Soc. Neurosci. Abstr. 13: 1147.

Gruol, D. L., C. Chavkin, R. J. Valentino, and G. R. Siggins (1983) Dynorphin-A alters the excitability of pyramidal neurons of the rat hippocampus in vitro. Life Sci. 33 (Suppl. I): 533-536.

Haug, F.-M. S. (1973) Heavy metals in the brain. Adv. Anat. Embryol 47: 1-71.

Herkenham, M., and S. McLean (1988) The anatomical relationship of opioid peptides and opiate receptors in the hippocampi of four rodent species. Natl. Inst. Drug Abuse Res. Monogr. Ser. 82: 33-47.

Houser, C. R., and J. E. Miyashiro (1988) Altered patterns of dynorphin-like immunoreactivity in the hippocampal formation of patients with temporal lobe epilepsy. Soc. Neurosci. Abstr. 14: 1033

Houser, C. R., R. W. Olsen, J. G. Richards, and H. Möhler (1988) Immunohistochemical localization of benzodiazepine/GABA $\mathrm{A}_{\mathrm{A}}$ receptors in the human hippocampal formation. J. Neurosci. 8: 1370-1383

Iadarola, M. J., C. Shin, J. O. McNamara, and H.-Y. T. Yang (1986) Changes in dynorphin, enkephalin and cholecystokinin content of hippocampus and substantia nigra after amygdala kindling. Brain Res. 365: 185-191.

Iwama, T., K. Ishihara, M. Satoh, and H. Takagi (1986) Different effects of dynorphin A on in vitro guinea pig hippocampal CA3 pyramidal cells with various degrees of paired-pulse facilitation. Neurosci. Lett. 63: 190-194.

Kanamatsu, T., J. Obie, L. Grimes, J. F. McGinty, K. Yoshikawa, S. Sabol, and J. S. Hong (1986a) Kainic acid alters the metabolism of met5-enkephalin and the level of dynorphin $A$ in the rat hippocampus. J. Neurosci. 6: 3094-3102.

Kanamatsu, T., J. F. McGinty, C. L. Mitchell, and J. S. Hong (1986b) Dynorphin- and enkephalin-like immunoreactivity is altered in limbic-basal ganglia regions of rat brain after repeated electroconvulsive shock. J. Neurosci. 6: 644-649.

Khachaturian, H., S. J. Watson, M. E. Lewis, D. Coy, A. Goldstein, and H. Akil (1982) Dynorphin immunocytochemistry in the rat central nervous system. Peptides 3: 941-954.

Lason, W., B. Przewlocka, L. Stala, and R. Przewlocki (1983) Changes in hippocampal immunoreactive dynorphin and neoendorphin content following intra-amygdalar kainic acid-induced seizures. Neuropeptides 3: 399-404.

Lauder, J. M., and E. Mugnaini (1980) Infrapyramidal mossy fibers in the hippocampus of the hyperthyroid rat. Dev. Neurosci. 3: 248 265.

Laurberg, S. (1979) Commissural and intrinsic connections of the rat hippocampus. J. Comp. Neurol. 184: 685-708.

Laurberg, S., and J. Zimmer (1981) Lesion-induced sprouting of hippocampal mossy fiber collaterals to the fascia dentata in developing and adult rats. J. Comp. Neurol. 200: 433-459.

Margerison, J. H., and J. A. N. Corsellis (1966) Epilepsy and the temporal lobes. Brain 89: 499-530.

McGinty, J. F., S. J. Henricksen, A. Goldstein, L. Terenius, and F. E.
Bloom (1983) Dynorphin is contained within hippocampal mossy fibers: Immunochemical alterations after kainic acid administration and colchicine-induced neurotoxicity. Proc. Natl. Acad. Sci. USA 80. 589-593.

Meldrum, B. S., and J. A. N. Corsellis (1985) Epilepsy. In Greenfield's Neuropathology, J. H. Adams, J. A. N. Corsellis, and L. W. Duchen, eds., pp. 921-950, Wiley, New York.

Moises, H. C., and J. M. Walker (1985) Electrophysiological effects of dynorphin peptides on hippocampal pyramidal cells in rat. Eur. $\mathrm{J}$. Pharmacol. 108: 85-98.

Mouritzen Dam, A. (1980) Epilepsy and neuron loss in the hippocampus. Epilepsia 21: 617-629.

Nadler, J. V., B. W. Perry, and C. W. Cotman (1980) Selective reinnervation of hippocampal area $\mathrm{CA} 1$ and the fascia dentata after destruction of CA3-CA4 afferents with kainic acid. Brain Res. 182. $1-9$.

Nadler, J. V., D. L. Tauck, D. A. Evenson, and J. N. Davis (1983) Synaptic rearrangements in the kainic acid model of Ammon's horn sclerosis. In Excitotoxins, K. Fuxe, P. Roberts, and R. Schwarcz, eds. pp. 256-270, Macmillan, London.

Przewlocki, R., W. Lason, R. Stach, and D. Kacz (1983) Opioid peptides, particularly dynorphin, after amygdaloid-kindled seizures. Reg. Peptides 6: 385-392.

Ramón y Cajal, S. (1893) The Structure of Ammon's Horn [L. M. Kraft, translator, Charles C Thomas, Springfield, 1968].

Represa, A., E. Tremblay, and Y. Ben-Ari (1987) Kainate binding sites in the hippocampal mossy fibers: Localization and plasticity. Neuruscience 20: 739-748.

Represa, A., G. Le Gall la Salle, and Y. Ben-Ari (1989a) Hippocampal plasticity in the kindling model of epilepsy in rats. Neurosci. Lett. 99: 345-350.

Represa, A., O. Robain, E. Tremblay, and Y. Ben-Ari (1989b) Hippocampal plasticity in childhood epilepsy. Neurosci. Lett. 99: 351355.

Ribak, C. E., L. Seress, and D. G. Amaral (1985) The development, ultrastructure and synaptic connections of the mossy cells of the dentate gyrus. J. Neurocytol. 14: 835-857.

Scharfman, H. E., and P. A. Schwartzkroin (1988) Electrophysiology of morphologically identified mossy cells of the dentate hilus recorded in guinea pig hippocampal slices. J. Neurosci. 8: 3812-3821.

Siggins, G. R., S. J. Henriksen, C. Chavkin, and D. Gruol (1986) Opioid peptides and epileptogenesis in the limbic system: Cellular mechanisms. In Advances in Neurology, Vol. 44, Basic Mechanisms of the Epilepsies, A. V. Delgado-Escueta, A. A. Ward, D. M. Woodbury, and R. J. Porter, eds., pp. 501-512, Raven, New York.

Sloviter, R. S. (1985) A selective loss of hippocampal mossy fiber Timm stain accompanies granule cell seizure activity induced by perforant path stimulation. Brain Res. 330: 150-153.

Sommer, W. (1880) Erkrankung des Ammonshorns als aetiologisches moment der epilepsie. Arch. Psychiatr. Nervenkr. 10: 631-675.

Stanfield, B. B. (1989) Excessive intra- and supragranular mossy fibers in the dentate gyrus of tottering $(\mathrm{tg} / \mathrm{tg})$ mice. Brain Res. 480: 294299.

Sternberger, L. A. (1979) Immunocytochemistry, Wiley, New York.

Sutula, T., H. Xiao-Xian, J. Cavazos, and G. Scott (1988) Synaptic reorganization in the hippocampus induced by abnormal functional activity. Science 239: 1147-1150.

Sutula, T., G. Cascino, J. Cavazos, I. Parada, and L. Ramirez (1989) Mossy fiber synaptic reorganization in the epileptic human temporal lobe. Ann. Neurol. 26: 321-330.

Swanson, L. W., J. M. Wyss, and W. M. Cowan (1978) An autoradiographic study of the organization of intrahippocampal association pathways in the rat. J. Comp. Neurol. 181: 681-716.

Tauck, D. L., and J. V. Nadler (1985) Evidence of functional mossy fiber sprouting in hippocampal formation of kainic acid-treated rats. J. Neurosci. 5: 1016-1022

Terrian, D. M., D. Johnston, B. J. Claiborne, R. Ansah-Yiadom, W. J. Strittmatter, and M. A. Rea (1988) Glutamate and dynorphin release from a subcellular fraction enriched in hippocampal mossy fiber synaptosomes. Brain Res. Bull. 21: 343-351.

Tortella, F. C. (1988) Endogenous opioid peptides and epilepsy: Quieting the seizing brain? Trends Pharmacol. Sci. 9: 366-372.

West, J. R. (1984) Ethanol exposure during development alters the terminal field of zinc-containing mossy fibers. In The Neurobiology of Zinc, C. J. Frederickson, G. A. Howell, and E. J. Kasarskis, eds., pp. 235-249, Liss, New York. 
West, J. R., and S. L. Dewey (1984) Mossy fiber sprouting in the fascia dentata after unilateral entorhinal lesions: Quantitative analysis using computer-assisted image processing. Neuroscience 13: 377-384.

Zimmer, J. (1971) Ipsilateral afferents to the commissural zone of the fascia dentata, demonstrated in decommissurated rats by silver impregnation. J. Comp. Neurol. 142: 393-416.
Zimmer, J. (1973) Changes in the Timm sulfide silver staining pattern of the rat hippocampus and fascia dentata following early postnatal deafferentation. Brain Res. 64: 313-326.

Zimmer, J. (1974) Long-term synaptic reorganization in rat fascia dentata deafferented at adolescent and adult stages: Observations with the Timm method. Brain Res. 76: 336-342. 